\title{
Comparative Analysis Of Dempster Shafer Method With Certainty Factor Method For Diagnose Stroke Diseases
}

\author{
Erwin Panggabean \\ Teknik Informatika STMIK Pelita Nusantara Medan, Medan, Sumatera Utara 20154, Indonesia \\ erwinpanggabean8@gmail.com
}

\section{ARTICLE INFO}

Article history:

Received: 2018-12-21

Revised: 2018-01-18

Accepted: 2018-03-19

Keywords:

certainty factor,

demstershafer,

comparison analysis

\begin{abstract}
The development of artificial intelligence technology that has occurred has allowed expert systems to be applied in detecting disease using programming languages. One in terms of providing information about a variety of disease problems that have recently been feared by Indonesian society, namely stroke. Expert system method used is dempster shafer and certainty factor method is used to analyze the comparison of both methods in stroke. Based on the analysis result, it is found that certainty factor is better than demster shafer and more accurate in handling the knowledge representation of stoke disease according to the symptoms of disease obtained from one hospital in medan city, uniqueness of algorithm that exist in both methods
\end{abstract}

Copyright (C) 2017 International Journal of Artificial Intelegence Research. All rights reserved.

\section{Introduction}

Stroke is one of the functions of acute neurologic dysfunction caused by vascular disorders and occurs suddenly, if it continues and is not treated promptly can result in total paralysis and even death. This causes stroke should be cautioned through early prevention [1]. Often difficult to obtain services and information because there is no expert stroke disease that can provide information on how to care for good health of the body, and how to choose the right action for himself or a family member who is suffering from stroke is a problem that is often a constraint in disease prevention stroke is more developed [2]. Although an expert in his field, but in reality an expert has limited memory and stamina of work which one factor may be due to the age of an expert and one day could have made a mistake on the diagnosis that can continue on the mistake of the solution taken [3]. Expert System is one of the progress of Artificial Intelligence (AI) or artificial intelligence that learn and be able to imitate human intelligence. Expert System is a branch of intelligence possessed by an expert to solve a particular problem [4]. Journal that discusses the Expert System diagnose stroke disease is indeed a lot with different methods. The difference of these journals with this research is the authors analyze the comparison of diagnosis results of Expert System of stroke by using Dempster Shafer method and Certainty Factor method [5]. Application of Expert System is used to replace the role of an expert stroke disease that does not necessarily exist any time when it is needed[6]. This is very helpful for people to consult whenever and wherever they are, about the types, symptoms, and ways of handling stroke. However by comparing the results of the diagnosis between the system with the results of an expert so that it can be known which method between the two methods are better in diagnosing stroke[7][8].

\section{Method}

The authors conducted a study at Bhayangkara Hospital Medan which is located on Jalan KH. Wahid Hasyim No.01, Merdeka, Medan, Medan City. The author conducted an interview with a specialist neurologist dr. Meity, M.B., SpS. In this hospital there is only one neurologist who still diagnose stroke patients in the patient manually, in the sense of stroke diagnosis results rely heavily 
on examination and decision of the expert. While the schedule of practice of neurologist at Bhayangkara Hospital is on Monday, Wednesday and Thursday of the week. So the patient must wait for the day in accordance with the doctor's schedule at the hospital to get the services of a specialist neurologist in poly nerve Hospital Bhayangkara. Here the author will explain about the use of two methods used to draw conclusions from the table type of disease and symptoms. There are four types of diseases directed by $\mathrm{K} 01, \mathrm{~K} 02, \ldots \mathrm{KO} 4$ and 30 symptoms addressed by G01, G02, ..., G030. Of the 30 symptoms compiled and 4 types of diseases are arranged as conclusions. This symptom is a knowledge base to make a conclusion into a goal. The following is a table of types of illnesses and symptoms[9].

\section{Result}

Where the bell value (believe) is the value of weight inputted by the expert. Sample case study: A father has the following symptoms: G03 (Difficulty speaking); G04 (Paralysis and sensory deficit on right arm and leg); G011 (high blood pressure); G016 (Can not move limbs at all). The first characteristic is blurred vision, which is characteristic of a brief brain attack (K01), brain tissue death (K02), and spontaneous subarkhnoid haemorrhage (K03).

$$
\begin{aligned}
& \mathrm{m} \_1\{\mathrm{~K} 01, \mathrm{~K} 02, \mathrm{~K} 03\}=0.4 \\
& \mathrm{~m}_{-} 1\{\Theta\}=1-0.4=0.6
\end{aligned}
$$

The second characteristic is the paralysis and sensory deficits of the right arm and leg that are characteristic of the classification of Death of Brain Network or K02.

$$
\begin{aligned}
& \mathrm{m} \_2\{\mathrm{~K} 02\}=0.6 \\
& \mathrm{~m} \_2\{\Theta\}=1-0.6=0.4
\end{aligned}
$$

The formula for calculating the new density using the formula :

$$
m 3(Z)=\sum_{X \cap Y=Z} m 1(X) m 2(Y)
$$

To facilitate the calculation of the sub-assemblies brought into shape Table. The first column contains all the sets on the first characteristic with $m_{-} 1$ as the density function. The first row contains all subsets of the second symptom with $m_{-}(2)$ as a density function.

\begin{tabular}{|l|l|l|}
\multicolumn{4}{|c}{ Density Function $\mathrm{m}_{-} 1$ and $\mathrm{m}_{-}(2)$} \\
\hline$m_{1} \quad\{\mathrm{~K} 01, \mathrm{~K} 02, \mathrm{~K} 03\}$ & $\{\mathrm{K} 01, \mathrm{~K} 02, \mathrm{~K} 03\}=$ & $\begin{array}{l}m_{2}\{\Theta 01, \mathrm{~K} 02, \mathrm{~K} 03\}=0,4 \\
=0,4\end{array}$ \\
\hline$m_{1}\{\Theta\}=0,24$ & 0,16 \\
\hline
\end{tabular}

$$
\begin{aligned}
& m_{3} \quad\{\mathrm{~K} 01, \mathrm{~K} 02, \mathrm{~K} 03\}=\frac{0,24+0,16}{1-0}=0,4 \\
& m_{3} \quad\{\mathrm{~K} 02\}=\frac{0,36}{1-0}=0,36 \\
& m_{3} \quad\{\Theta\}=\frac{0,24}{1-0}=0,24
\end{aligned}
$$

The third characteristic is high blood pressure, which is characteristic of the Classification of Brain Attack (K01), Death of Brain Network (K02), Spontaneous Subarkhnoid Bleeding (K03), Intra-Cellular Bleeding (K04).

$$
\begin{aligned}
& m_{4}\{\mathrm{~K} 01, \mathrm{~K} 02, \mathrm{~K} 03, \mathrm{~K} 04\}=0,6 \\
& m_{4}\{\Theta\}=1-0,6=0,4
\end{aligned}
$$

Then we have to recalculate the new density values for each subset with the $m \_5$ density function. As in the previous step, we compile the table with the first column containing the result set 
of combinations of characteristics 1 , characteristic 2, and characteristic 3, with the density function $\mathrm{m}_{-} 3$. Whereas the first line contains subsets on characteristics 1 , characteristic 2 , characteristic 3 , and characteristic 4 with the density function $\mathrm{m}_{-} 4$.

Table 1. Density Function $\mathrm{m}_{-} 3$ and $\mathrm{m}_{-}$(4)

\begin{tabular}{|l|l|l|}
\hline & $\begin{array}{l}m_{4}\{\mathrm{~K} 01, \mathrm{~K} 02, \mathrm{~K} 03, \mathrm{~K} 04\} \\
0,6\end{array}$ & $m_{4}\{\Theta\}=0,4$ \\
\hline $\begin{array}{l}m_{3}\{\mathrm{~K} 01, \mathrm{~K} 02, \mathrm{~K} 03\}= \\
0,4\end{array}$ & $\{\mathrm{~K} 01, \mathrm{~K} 02, \mathrm{~K} 03\}=0,24$ & $\{\mathrm{~K} 01, \mathrm{~K} 02, \mathrm{~K} 03\}=0,16$ \\
\hline$m_{3}\{\mathrm{~K} 02\}=0,36$ & $\{\mathrm{~K} 02\}=0,216$ & $\{\mathrm{~K} 02\}=0,144$ \\
\hline$m_{3}\{\Theta\}=0,24$ & $\begin{array}{l}\{\mathrm{K} 01, \mathrm{~K} 02, \mathrm{~K} 03, \mathrm{~K} 04\}= \\
0,144\end{array}$ & $\{\Theta\}=0,096$
\end{tabular}

Next is calculated the new density for combination (m_5):

$$
\begin{aligned}
& m_{5}\{\mathrm{~K} 01, \mathrm{~K} 02, \mathrm{~K} 03\}=\frac{0,24+0,16}{1-0,096}=0,4424778761 \\
& m_{5}\{\mathrm{~K} 02\}=\frac{0,216+0,144}{1-0,096}=0,3982300885 \\
& m_{5}\{\mathrm{~K} 01, \mathrm{~K} 02, \mathrm{~K} 03, \mathrm{~K} 04\}=\frac{0,144}{1-0,096}=0,1592920354 \\
& m_{5}\{\Theta\}=\frac{0,096}{1-0,096}=0,1061946903
\end{aligned}
$$

The fourth characteristic is that it can not move the limbs at all which is characteristic of the classification of Brain Death Network (K02).

$$
\begin{aligned}
& \mathrm{m}_{-} 6\{\mathrm{~K} 02\}=0.8 \\
& \mathrm{~m} \_6\{\Theta\}=1-0.8=0.2
\end{aligned}
$$

Table 2. Density Function $\mathrm{m}_{-} 5$ and $\mathrm{m} \_6$

\begin{tabular}{|l|l|l|}
\hline & $m_{6}\{\mathrm{~K} 02\}=0,8$ & $m_{6}\{\Theta\}=0,2$ \\
\hline $\begin{array}{l}m_{5}\{\mathrm{~K} 01, \mathrm{~K} 02, \mathrm{~K} 03\}= \\
0,4424778761\end{array}$ & $\begin{array}{l}\{\mathrm{K} 01, \mathrm{~K} 02, \mathrm{~K} 03\}= \\
0,3539823009\end{array}$ & $\begin{array}{l}\{\mathrm{K} 01, \mathrm{~K} 02, \mathrm{~K} 03\}= \\
0,0884955752\end{array}$ \\
\hline $\begin{array}{l}m_{5}\{\mathrm{~K} 02\} \\
=0,3982300885\end{array}$ & $\{\mathrm{~K} 02\}=0,3185840708$ & $\{\mathrm{~K} 02\}=0,0796460177$ \\
\hline $\begin{array}{l}m_{5} \\
\text { K01,K02,K03,K04\} }= \\
0,1592920354\end{array}$ & $\begin{array}{l}\{\mathrm{K} 01, \mathrm{~K} 02, \mathrm{~K} 03, \mathrm{~K} 04\}= \\
0,1274336283\end{array}$ & $\begin{array}{l}\{\mathrm{K} 01, \mathrm{~K} 02, \mathrm{~K} 03, \mathrm{~K} 04\} \\
=0,0318584071\end{array}$ \\
\hline$m_{5}\{\Theta\}=0,106194690$ & $\begin{array}{l}\{\mathrm{K} 01, \mathrm{~K} 02, \mathrm{~K} 03\}= \\
0,084955752\end{array}$ & $\{\Theta\}=0,021238938$ \\
\hline
\end{tabular}

Here the author will again lift the example of the same case study that is a father who has symptoms of the disease as follows: G03 (Difficulty speaking); G04 (Paralysis and sensory deficit on the right arm and limb); G011 (high blood pressure); G016 (Can not move arms and legs at all).

$$
\mathrm{CF}[\mathrm{h}, \mathrm{e}]=\mathrm{MB}[\mathrm{h}, \mathrm{e}]-\mathrm{MD}[\mathrm{h}, \mathrm{e}]
$$

To calculate the value of Dempster Shafer stroke is selected using the Measure of Belief (MB) and Measure of Disbelief (MD) values that have been determined on each symptom.

Table 3. Measure Table

\begin{tabular}{|l|c|c|}
\hline \hline \multicolumn{1}{|c|}{ Symptom Name } & MB Values & MD Values \\
\hline Difficulty speaking. & 0,4 & 0,04 \\
\hline $\begin{array}{l}\text { Paralysis and sensory } \\
\text { deficit in the right arm } \\
\text { and limb. }\end{array}$ & 0,6 & 0,06 \\
\hline High blood pressure. & 0,6 & 0,06 \\
\hline $\begin{array}{l}\text { Can not move arms and } \\
\text { legs at all. }\end{array}$ & 0,8 & 0,08 \\
\hline
\end{tabular}


CF Certainty factor values:

$\mathrm{G} 02=\mathrm{G} 01+(\mathrm{G} 02 \times(1-\mathrm{G} 01))$

$=0,4+(0,6 \times(1-0,4))$

$=0,4+(0,6 \times(0,6))$

$=0,4+0,36$

$=0,76$

$\mathrm{G} 03=\mathrm{G} 02+(\mathrm{G} 03 \times(1-\mathrm{G} 02))$

$=0,76+(0,6 \times(1-0,76))$

$=0,76+(0,6 \times(0,24))$

$=0,76+0,144$

$=0,904$

$\mathrm{G} 04=\mathrm{G} 03+(\mathrm{G} 04 \times(1-\mathrm{G} 03))$

$=0,904+(0,8 \times(1-0,904))$

$=0,904+(0,8 \times(0,096))$

$=0,904+0,0768$

$=0,9808$

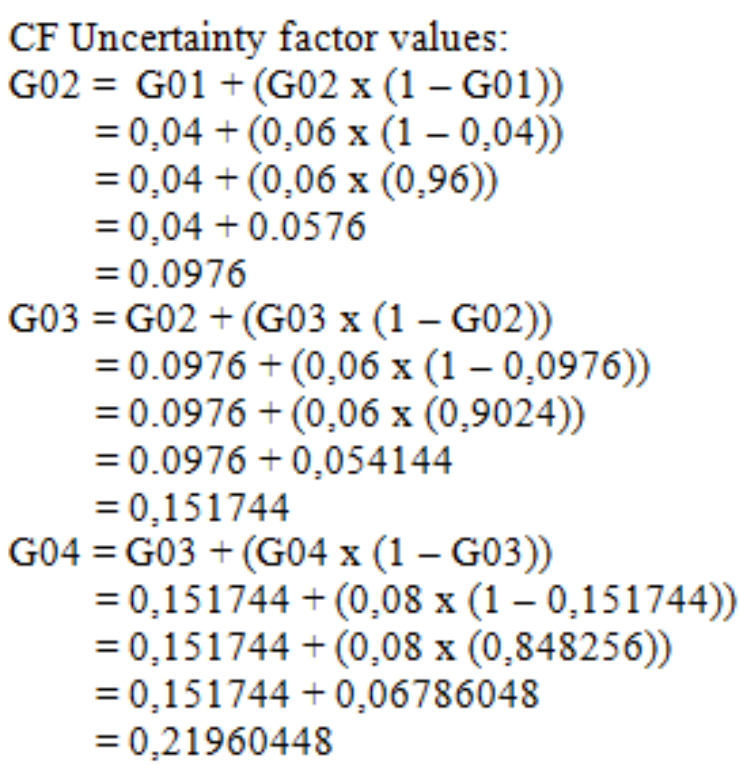

To find the value of CF can be obtained from: $\mathrm{MB}$ value $=0.9808-\mathrm{MD}$ value $=0.21960448=$ 0.76119552.Diagnosis Result: You are indicated by Death of Brain Disease (Thick Infarction), CF value: 0.76119552

Improvement of infant neonate infarction condition if lag time between attack and handling still less than three hours and immediately opening the blockage, then can still be expected optimal recovery in patient. In addition to this, efforts to reduce risk factors for the occurrence of infarct among other things, by maintaining the stability of blood pressure, maintaining the balance of weight badaa, as well as the stability of blood sugar and cholesterol levels by improving diet and not smoking.

\section{Conclusion}

Based on the results of analysis of stroke diagnosis result between Dempster Shafer method with Certainty Factor method, it can be concluded, Dempster Shafer's method of diagnosing stroke in Medan City is better than Certainty Factor method. Level of accuracy of expert system diagnosis with Certainty Factor method is $80 \%$, while expert system diagnosis result with Dempster Shafer method is $85 \%$. the amount of Certainty Factor (CF) value generated from the Certainty Factor method and the density value generated from the Dempster Shafer method and the diagnosis result of each method determined by the number of matches between the input symptoms and the belief value of each symptom. The magnitude of the Certainty Factor (CF) value resulting from the Certainty Factor method of each possible illness is always between 0 and 1, with the highest Certainty Factor value being the strongest possible diagnosis of the disease.

\section{References}

[1] X. Wan and J. Zhang, "CTSUM : Extracting More Certain Summaries," Acm Sigir, 2014.

[2] P. M. Prihatini, I. K. Gede, and D. Putra, "Fuzzy Knowledge-based System with Uncertainty for Tropical Infectious Disease Diagnosis," IJCSI Int. J. Comput. Sci. Issues, 2012.

[3] R. L. Morgan et al., "GRADE: Assessing the quality of evidence in environmental and occupational health," Environ. Int., 2016.

[4] J. Dou et al., "An integrated artificial neural network model for the landslide susceptibility assessment of Osado Island, Japan," Nat. Hazards, 2015.

[5] C. Wu and D. Barnes, "Formulating partner selection criteria for agile supply chains: A DempsterShafer belief acceptability optimisation approach," Int. J. Prod. Econ., 2010.

[6] H. Liu, X. Wu, and S. Zhang, "Neighbor selection for multilabel classification," Neurocomputing, 2016.

[7] A. Kornejady, M. Ownegh, O. Rahmati, and A. Bahremand, "Landslide susceptibility assessment 
using three bivariate models considering the new topo-hydrological factor: HAND," Geocarto International, 2017.

[8] Y. Deng and Y. Ouyang, "A belief revision method based on argumentative dialogue model," in ICCSE 2016 - 11th International Conference on Computer Science and Education, 2016.

[9] Y. Kajiwara, H. Kimura, and T. Oyabu, "Mood Prediction in Consideration of Certainty Factor Using Multilayer Deep Neural Network and Storage-Type Prediction Models," Sensors Mater., 2016. 